\title{
Gerenciamento de comitês de bacia: desafios e potencialidades
}

\author{
Management committees bowl: challenges and potential \\ Pedro Daniel da Cunha Kemerich', Luciana Gregory Ritter², Vinicius Ferreira Dulac ${ }^{3}$ \\ ' Coordenador do Curso de Engenharia Ambiental da Universidade Federal de Santa Maria/CESNORS, Frederico Westphalen, Brasil. \\ ${ }_{2}^{2}$ Aluna de graduação do curso de Engenharia Ambiental e Sanitária, Universidade Federal de Santa Maria, Santa Maria, Brasil. \\ ${ }^{3}$ Mestre em Recursos Hídricos e Saneamento Ambiental, Universidade Federal de Santa Maria, Santa Maria, Brasil.
}

\begin{abstract}
Resumo
O aumento da degradação ambiental leva a busca por novas metodologias de gestão que visem o desenvolvimento sustentável. Nesse contexto, surgem os comitês de bacia hidrográfica, os quais estão previstos no Sistema Nacional de Gerenciamento de Recursos Hídricos, sendo este sistema instituído pela Política Nacional de Recursos Hídricos. Os comitês são órgãos colegiados onde são debatidas as questões regionais referentes à gestão das águas, fazendo parte desse sistema representantes da União, dos Estados e do Distrito Federal cujos territórios se situem, ainda que parcialmente, em suas respectivas áreas de atuação, dos Municípios situados, no todo ou em parte, em sua área de atuação, dos usuários das águas de sua área de atuação e das entidades civis de recursos hídricos com atuação comprovada na bacia. Os comitês possuem várias atribuições, as quais estão descritas no art. 19 da Lei Estadual n $10.350 / 94$ - no caso da Política de Recursos Hídricos do Estado do Rio Grande do Sul cabendo destacar a sua função de dirimir conflitos. Possuindo o potencial de sintetizar as diretrizes, o comitê configura-se em um espaço institucional o qual pode ser caracterizado como uma arena de tomada de decisões para o compartilhamento de interesses e integração de políticas dos setores usuários da água e da sociedade civil. Assim, o êxito de seu funcionamento em certa medida significa o êxito da própria política das águas, principalmente no que se refere á gestão descentralizada e participativa. O grande desafio é que esses espaços sejam efetivamente públicos, tanto no seu formato quanto nos resultados, e para tal os comitês devem passar por uma avaliação contínua de sua estrutura social, a partir de uma análise de suas ações enquanto órgãos que devem funcionar como um fórum integrador de políticas, promovendo a gestão integrada e sustentável dos recursos naturais da bacia hidrográfica, conforme as diretrizes da Política de Recursos Hídricos.
\end{abstract}

Palavras-chave: Comitês. Conflitos. Gestão.

\begin{abstract}
Increased environmental degradation leads to the search for new management methods aimed at sustainable development. In this context, arise river basin committees, which are provided for in the National Water Resources Management, which is the system created by the National Water Resources. The committees are collegiate bodies which are discussed regional issues related to water management as part of this system representatives of the Union, the states and the Federal District whose territories are situated, even partially, in their respective areas, the municipalities located in whole or in part, in its area of operation, the water users in its area of operation and civil entities of water resources with proven activities in the basin. The committees have multiple assignments, which are described in art. 19 of the State Law 10.350/94 - in the case of water resources policy of the State of Rio Grande do Sul fitting highlight its function of resolving conflicts. Possessing the potential to synthesize the guidelines, the committee set up in an institutional space which can be characterized as a decision-making arena for sharing interests and political integration of the sectors of water users and civil society. Thus, the success of its operation to some extent means the success of own water policy, especially with regard to the management decentralized and participatory. The challenge is that these spaces are effectively public, both in its format as the results, and such committees must undergo continuous evaluation of their social structure, from an analysis of their actions while organs that must function as a forum integrator policies, promoting the integrated and sustainable management of natural resources of the watershed, according to the guidelines of Water Resources.
\end{abstract}

Keywords: Committees. Conflicts. Management 


\section{INTRODUÇÃO}

À medida que aumentam os efeitos da degradação ambiental sobre a disponibilidade de recursos hídricos, a gestão de bacias hidrográficas assume crescente importância no Brasil (JACOBI e BARBI, 2007). Uma alternativa para todos esses problemas seria $\mathrm{O}$ desenvolvimento de sistemas adequados de gestão e de procura permanente de inovações tecnológicas, e na adoção de medidas estruturais e não-estruturais para a gestão integrada e preditiva das águas (TUNDISI, 2006).

Ao longo da década de noventa, a União e a maioria dos estados aprovaram leis que reorganizaram o sistema de gestão de recursos hídricos. Ocorre a mudança de uma gestão institucionalmente fragmentada para uma legislação integrada e descentralizada, principalmente com a edição da Lei Federal n. 9.433, em 8 de janeiro de 1997, a qual institui a Política Nacional de Recursos Hídricos (PNRH) e a criação da Agência Nacional de Águas (ANA), em 2000. Esta reorganização do sistema substitui práticas profundamente arraigadas de planejamento tecnocrático e autoritário. O novo sistema reconhece a água como bem econômico, preconiza uma gestão integrada e descentralizada dos usos múltiplos da água, e requer negociações entre órgãos de diferentes níveis de governo (federal, estadual e local), usuários e a sociedade civil organizada (JABOBI, 2006).

Nesse sentido, surgem os Comitês de Bacias Hidrográficas - CBH's, os quais estão previstos no Sistema Nacional de Gerenciamento de Recursos Hídricos - SINGRH, sendo este sistema instituído pela PNRH. São órgãos colegiados onde são debatidas as questões regionais referentes à gestão das águas.

Os comitês configuram-se como instituições relativamente recentes no Brasil, criadas nas duas últimas décadas do século XX, em um contexto de descentralização da gestão implementada pelo Estado, notadamente a partir da Constituição Federal de 1988 - CF/1988, onde a competência de alguns aspectos da gestão de recursos hídricos, bem como da gestão ambiental, está relacionada aos três entes federados, dispostas no art. 23 da CF.

Segundo a CF, os rios que cruzam mais de um Estado ou País são de domínio Federal, enquanto os demais têm dominialidade Estadual. Deste modo, os Estados instituíram suas respectivas Políticas de Recursos Hídricos, com destaque para o pioneirismo dos Estados São Paulo e Ceará, que instituíram em conjunto com outros oito Estados suas Leis das águas em período anterior a 1997 - ano da promulgação da Lei Federal 9.433/1997.

Assim, a atribuição de integrar e gerir o Sistema de Recursos Hídricos refere-se geralmente a órgãos da administração direta no âmbito dos Estados, porém regulamentos específicos regionais são determina- dos nos Comitês. Suas deliberações assumem caráter legal mediante o encaminhamento e a aprovação dos Conselhos de Recursos Hídricos (instancias máximas do Sistema, onde há representações dos Comitês e Secretarias de Estado).

Apesar de a implantação desse sistema de gerenciamento ainda ser relativamente recente, a partir dele pode-se perceber que os problemas relacionados aos recursos hídricos têm fomentado a modificação das instituições, das práticas sociais e consequentemente tem influência sobre a organização do espaço geográfico representado pela bacia (LIMA, 2005).

A história do seu surgimento e as demandas sociais que envolvem esta nova forma de gerenciamento geram uma expectativa de que as práticas de organização espacial sejam realizadas de uma forma diversa daquela que tradicionalmente ocorria como tentativas de planejamento e gestão do território (ANDREOZZI, 2005).

O sistema de funcionamento dos comitês está baseado no tripé descentralização, participação e integração, e a ênfase é quanto aos aspectos qualidade e quantidade das águas através de ações que promovam os usos múltiplos dos recursos hídricos. Este é um processo ainda em consolidação, estando a prioridade dos organismos de bacia centrada na criação dos instrumentos necessários para a gestão (JACOBI; BARBI, 2007).

Dessa maneira, o presente trabalho tem por objetivo realizar uma análise a cerca da gestão dos comitês de bacia, sua forma de atuação, desafios e potencialidades futuras.

\section{A COMPOSIÇÃO DOS COMITÊS DE BACIA HIDROGRÁFICA}

O Brasil inspirou-se no sistema francês de gerenciamento, o qual conta com Comitês de Bacia integrados em partes iguais por representantes dos usuários, das coletividades locais e do governo central, e também com as Agências de Bacia, que contam com autonomia financeira para fornecer subsídios e conceder empréstimos a pessoas físicas e jurídicas visando à realização de obras de interesse comum (BARBOSA, 2003). No entanto, o sistema brasileiro apresenta maior descentralização para o nível dos Estados e dos municípios, o que pode estar influenciando no gerenciamento dos recursos hídricos, de forma a minimizar a implantação de instrumentos de gestão, o fornecimento de recursos e a participação popular.

Nota-se que, uma maior descentralização deveria resultar em uma maior participação popular. Assim, uma hipótese é que, sem um controle ou avaliação da qualidade dessa participação (principalmente em termos de representatividade) e dificuldades do Estado em negociar e aplicar as decisões tomadas pelo Comitê, pode resultar na referida minimização. 
Segundo o Art. 39 da Lei 9.433, os comitês de bacia hidrográfica devem ser compostos por representantes:

I - da União;

II - dos Estados e do Distrito Federal cujos territórios se situem, ainda que parcialmente, em suas respectivas áreas de atuação; III - dos Municípios situados, no todo ou em parte, em sua área de atuação;

IV - dos usuários das águas de sua área de atuação;

$\mathrm{V}$ - das entidades civis de recursos hídricos com atuação comprovada na bacia.

A representação do conjunto dos representantes dos poderes executivos da União, dos Estados, Distrito Federal e Municípios, está limitada à metade do total de membros (art. 39, $\S 1^{\circ}$ ) e deverá obedecer o limite de $40 \%$ do total de votos no comitê (art. $8^{\circ}$,I, da Resolução $n^{\circ}$ 5).

Já, nos comitês do Estado do Rio Grande do Sul o grupo referente ao Poder Público é representado por entidades Estaduais e Federais, correspondendo a $20 \%$ dos titulares indicados (Art. $13^{\circ}$ e $14^{\circ}$ da PERH (Lei Estadual 10.350/1994)).
No Estado do RS o poder público municipal tem participado da composição dos comitês junto a categoria usuários da água como, por exemplo, no Comitê do rio Santa Maria e no Comitê do rio Camaquã (CBHSM, 2013; CBHC,2013). Isto indica que dos índices de representação do Poder Público no RS estão relacionados a ausência de participação na composição dos Comitês de Bacia por parte de entidades Estaduais e Federais. Apesar de o Poder Público possuir uma representação limitada nos comitês, o estado do Rio Grande do Sul têm avançado significativamente no processo de implantação dos comitês de bacia hidrográfica (HAASE, 2005), exemplo disto é que a totalidade das Bacias Hidrográficas de Gerenciamento do RS ( $n=25)$ possuem Comitês instalados.

\section{ATRIBUIÇÕES DOS COMITÊS DE BA- CIA}

É em função da escassez que se atribui à água valor econômico. Deste modo, observa-se que somente a partir de uma unidade física de planejamento em que possam ser considerados os efeitos do balanço hídrico (as entradas e as saídas de água da bacia, as influencias

Quadro 1 - Descrição dos instrumentos de gestão de recursos hídricos

\begin{tabular}{|l|l|}
\hline \multicolumn{1}{|c|}{$\begin{array}{c}\text { Instrumento de } \\
\text { gestão }\end{array}$} & \multicolumn{1}{|c|}{ Descrição } \\
\hline $\begin{array}{l}\text { Plano de Recursos } \\
\text { Hídricos }\end{array}$ & $\begin{array}{l}\text { É o documento/plano diretor no qual são dispostas as } \\
\text { prioridades de gestão, metas e cenários da situação de } \\
\text { disponibilidade quantitativa e qualitativa dos recursos hídricos, } \\
\text { tem função de orientar a implementação dos demais } \\
\text { instrumentos (Art. 6). }\end{array}$ \\
\hline $\begin{array}{l}\text { Enquadramento dos } \\
\text { corpos de água em } \\
\text { classes segundo os } \\
\text { usos preponderantes }\end{array}$ & $\begin{array}{l}\text { Significa definir os usos que se deseja fazer destes recursos e } \\
\text { assegurar às águas a qualidade compatível com os usos mais } \\
\text { exigentes a que se destinarem (Art. 9) }\end{array}$ \\
\hline $\begin{array}{l}\text { Outorga de uso dos } \\
\text { recursos hídricos }\end{array}$ & $\begin{array}{l}\text { Concede o direito ao usuário pelo Estado para o uso da água (a } \\
\text { água é dividida segundo "quotas" de uso), considerando o } \\
\text { balanço entre a disponibilidade e a demanda e aspectos de } \\
\text { qualidade da água. }\end{array}$ \\
\hline $\begin{array}{l}\text { Cbjetiva reconhecer a água como bem econômico incentivando } \\
\text { a racionalização no seu uso e obter recursos financeiros para o } \\
\text { financiamento dos programas e intervenções contemplados nos } \\
\text { planos de recursos hídricos (Art. 19). Visa aplicar o Princípio do } \\
\text { poluidor pagador, sendo o valor cobrado obrigatoriamente } \\
\text { investido na bacia, de acordo com as prioridades definidas no } \\
\text { Plano de bacia. }\end{array}$ \\
\hline $\begin{array}{l}\text { Sistema de } \\
\text { informações sobre os } \\
\text { Recursos Hídricos }\end{array}$ & $\begin{array}{l}\text { Sistema de coleta, tratamento, armazenamento e recuperação de } \\
\text { informações sobre recursos hídricos e fatores intervenientes em } \\
\text { sua gestão (Art. 25). }\end{array}$ \\
\hline
\end{tabular}

Fonte: adaptado da Lei Federal no 9.433/1997. 
dos elementos antrópicos, físicos, químicos e bióticos) é possível alocar de maneira eficiente os recursos hídricos entre os seus usuários.

Devendo funcionar como fórum integrador de políticas, o comitê tem o potencial de articular a política de recursos hídricos com a política ambiental, socioeconômica e de uso do solo, entre outras, possibilitando gerenciar de forma integrada e sustentável a utilização e conservação dos recursos naturais da bacia hidrográfica (MASCARENHAS, 2006).

Seus desafios na tomada de decisões passam pelos atores e interesses envolvidos nos diferentes níveis hierárquicos do sistema. Estes atores devem buscar soluções que atendam, ao máximo possível, os princípios da Lei 9.433/97, os quais estão sintetizados no quadro 1, cabendo ao comitê auxiliar na implantação destes instrumentos de gestão. Encontram-se grifados no quadro 1 aspectos que mostram o fundamento econômico neoclássico que envolve os instrumentos de gestão da Política das Águas.

Como instrumento fundamental para a segurança da distribuição das águas em uma bacia de gerenciamento, destaca-se a importância do sistema de informações pelo subsidio conferido pelo mesmo aos critérios de outorga e enquadramento. Além do embasamento para a elaboração do Plano de bacia.

No enquadramento definem-se parâmetros de qualidade por trecho do rio, de acordo com os usos preponderantes e as necessidades atuais e futuras da sociedade. Tais necessidades são avaliadas através de estratégias participativas tais como reuniões dos Comitês de bacia e audiências públicas, por exemplo, as quais devem se relacionar com o Plano de bacia.

É importante observar o volume de água outorgada o qual não deve comprometer uma vazão de diluição definida para manutenção dos parâmetros de qualidade do enquadramento. Além disso, deve equacionar a administração da oferta (disponibilidade) com a demanda de acordo com as prioridades definidas no Plano de bacia.

O instrumento cobrança tem dentre seus objetivos, incentivar o uso racional das águas e financiar as ações definidas no Plano de bacia.

Observa-se que os instrumentos são integrados, principalmente através do Plano de bacia e devem ser implantados em um caráter de interdependência.

Por outro lado, destaca-se que estes demandam não só capacidades técnicas, políticas e institucionais, mas também tempo para sua definição e operacionalização. Pois, antes de tudo é um processo organizativosocial, o qual demanda participação e aceitação dos agentes envolvidos.

Neste âmbito, os comitês têm atribuições, as quais estão especificadas no art. 19 da Lei no 10.350/94, tais como promover o debate das questões relacionadas aos recursos hídricos da bacia, aprovar e acompanhar a execução do Plano de Recursos Hídricos da Bacia, estabelecer os mecanismos de cobrança pelo uso de recursos hídricos e sugerir o valor a ser cobrado, estabelecer critérios e promover o rateio de custo das obras de uso múltiplo, de interesse comum ou coletivo, arbitrando em primeira instância, os conflitos relacionados a recursos hídricos. Em suma, os comitês devem participar comunitariamente do Sistema Estadual de Recursos Hídricos - SERH como um todo, configurando-se em um espaço onde se possa incorporar democraticamente na tomada de decisão a vertente comunitária, e, não somente, a vertente técnica proveniente de técnicos do governo ou de empresas contratadas (DULAC et al., 2012).

Para tanto, os comitês necessitam desenvolver mecanismos de gestão das águas que façam convergir os diferentes setores econômicos, com as políticas de grupos de interesse, e as questões legislativas e executivas governamentais.

\section{DESAFIOS NA GESTÃO DOS COMITÊS}

Em virtude de assimetrias sociais, dos impactos sobre o meio ambiente e das formas de resistência, organização e participação dos diversos atores envolvidos (FRACALANZA et al., 2009), o Comitê, como parte de um sistema de gestão das águas de caráter descentralizado e centrado na noção de poder social, que media as relações entre Estado e Sociedade Civil, encontra-se envolvido em um espaço de construção de alianças e cooperação, o qual é permeado (o poder social) também por conflitos.

Os comitês tem enfrentado dificuldades na sua implementação, como é relatado por Costa (2002) que, com base em sua experiência, afirma que os problemas dos comitês começam com a ausência de pautas concretas, diminuindo o número de participantes das reuniões, e com a burocracia do Estado. Já Maciel (2002) cita a descontinuidade de atuação como prejudicial ao avanço da política e do sistema de gestão.

Visões divergentes do processo e dos objetivos por parte dos diferentes membros tem dificultado a busca de soluções mais equitativas dentro dos comitês. Cabe ressaltar que numa negociação em bases sócio-técnicas entre atores diferenciados, configuram-se assimetrias na situação dos atores, tanto em termos econômicos, como sociais e políticos, o que coloca a questão da capacidade de negociação e de estabelecer pactos. Dada a complexidade do processo e das dificuldades de se consolidar um parâmetro de cidadania ambiental, em muitas casos as lógicas de gestão ainda centram numa forte prevalência do componente técnico como referencial de controle (JACOBI; BARBI, 2007). 
Os comitês estão centrados na participação social, sendo esta outra dificuldade para o seu funcionamento, e para que ela ocorra verdadeiramente necessita de representação e representatividade de seus membros. Segundo Meier (2011), a falta de representatividade dos comitês junto à sociedade pode estar ancorada na falta de representatividade da sociedade junto aos comitês.

No âmbito da Gestão Integrada de Bacias Hidrográficas - GIBH, disparidades na composição dos comitês também constituem um importante problema, não permitindo que o comitê gerencie os recursos hídricos da bacia eficientemente considerando a participação de todos os agentes sociais que são influenciados direta ou diretamente pela disponibilidade de água.

Para garantir uma participação mais abrangente da sociedade civil na gestão dos recursos hídricos, faz-se necessária uma redefinição do papel de poder em que se situam os peritos em relação aos leigos e não só um questionamento das relações de poder econômico ou uma abertura de maior espaço para a sociedade civil nos processos decisórios. No cotidiano das práticas de implementação da legislação têm-se configurado redes sociais diversas para coletar informações, formar opiniões, legitimar pontos de vista, que contínua e inevitavelmente implicam redefinições das relações de poder (GUIVANT; JACOBI, 2003).

O processo de financiamento dos comitês é outro segmento que não funciona, dificultando a sua atuação, e este aspecto só terá mudanças quando se instituir a cobrança pelo uso dos recursos hídricos (PAIM, 2010).

A causa fundamental geradora de conflitos entre os atores do poder público na gestão das águas, seja ele municipal, estadual ou federal, é a dificuldade de conciliação de papéis. Principalmente em um país continental como o Brasil, com problemas sócioeconômicos graves, grandes desigualdades regionais, e carência de dados hidroambientais, não é fácil concatenar os poderes de formulação de políticas ambientais com a operacionalização dos poderes de outorga pelo uso da água e de fiscalização (poder de polícia), e de todos estes com os interesses econômicos multisetoriais (MAGALHÃES Jr., 2001).

Assim, pode-se afirmar que os conflitos são inerentes ao processo de gestão e podem ser objetos de negociação ou não, dependendo principalmente de aspectos sociais e culturais dos agentes e da estrutura, ou seja, das relações de poder que se estabelecem dentro do Comitê.

Kemerich et al. (2013) ao analisar a gestão do comitê de gerenciamento de recursos hídricos na bacia hidrográfica dos rios Vacacaí e Vacacaí-Mirim, observaram que no decorrer do período avaliado, muitos conflitos foram mediados através de ações referentes a planos/estudos e projetos do comitê envolvendo as entidades membro, além de pessoas e entidades com interesse na temática ambiental e de recursos hídricos, demonstrando a atuação do comitê a qual é de fundamental importância para o sucesso na gestão dos recursos hídricos.

Se aspectos como representatividade, motivação e organização/articulação da participação não forem efetivos, é possível que uma situação de conflito exista, porém não seja abordada pelos agentes sociais.

Por outro lado, o órgão Estatal responsável deve dispor de uma estrutura adequada para manter uma política (a de recursos hídricos) que tem como regra geral proporcionar a harmonização entre os usos múltiplos e competitivos da água, considerando a limitada e aleatória disponibilidade temporal e espacial dos recursos hídricos.

\section{POTENCIALIDADES NA GESTÃO DE RECURSOS HÍDRICOS}

Os comitês desempenham um papel estratégico na Política de Recursos Hídricos, pois tem o potencial de sintetizar suas diretrizes. No caso da Política de Recursos Hídricos gaúcha, a qual preconiza uma gestão descentralizada - no nível espacial das bacias, participativa e integrada - o Comitê de Bacia configura-se em um espaço institucional o qual pode ser caracterizado como uma arena de tomada de decisões para o compartilhamento de interesses e integração de políticas dos setores usuários da água e da sociedade civil. Assim, o êxito de seu funcionamento em certa medida significa o êxito da própria política das águas. Sua legitimidade tem sido conferida não apenas pela própria lei e pelas políticas nacional e estaduais, mas por políticas paralelas que têm sido implementadas tanto no âmbito nacional como no estadual e, em alguns casos, até no municipal (CARDOSO, 2003).

Ao atribuir aos comitês o gerenciamento dos recursos hídricos centralizado, o mesmo torna-se possível um novo mecanismo de cooperação multilateral entre a esfera federal e as demais, na solução de problemas regionais, sobretudo nas regiões conturbadas (NASCIMENTO; VILLAÇA, 2008).

Nesse sentido, a ANA está propondo a construção de acordos sociais estabelecidos nos comitês de bacia hidrográfica, visando a formação de consensos sobre a utilização dos recursos hídricos e evitando assimetrias entre usuários ou entre os órgãos gestores, minimizando dessa forma, os conflitos (PEREIRA; JOHNSSON, 2005).

O processo de adaptação às condições específicas de cada bacia envolve mais do que uma leitura "correta" das condições e recursos locais. Para os atores comprometidos com a governança participativa, é também uma questão de seduzir outros atores, dentro e fora 
dos comitês, com o intuito de fazer funcionar o sistema descentralizado de gestão (ABERS; KECK, 2004).

Os Comitês teriam de sofrer reformulações importantes do ponto de vista do compartilhamento, já que a Sociedade Civil pode ter papel expressivo na definição de conteúdos. Para a efetiva participação, um dos principais desafios é a capacitação dos membros. Isto abre um importante espaço para buscar elementos homogeneizadores nas práticas e para fortalecer uma rede dinâmica de troca de experiências e práticas inovadoras (JACOBI; FRACALANZA, 2005).

Em análise da gestão do comitê de gerenciamento de recursos hídricos na bacia hidrográfica dos rios Vacacaí e Vacacaí-Mirim, Kemerich et al. (2013) sugerem que um exemplo de atividade que poderia aumentar a amplitude das relações sociais do comitê na sociedade, tornando-se mais inclusiva é a manutenção de um site na web, contendo documentos oficiais do órgão, legislações, ações do comitê e espaço para discussões. Com isso, o órgão implementa uma ação de transparência e prestação de contas junto a seus representados, o que o confere uma maior legitimidade para articular e representar os interesses da bacia.

O capital social criado em uma bacia hidrográfica dotada dos instrumentos de gestão de recursos hídricos (plano, comitê, cobrança, agência), pode ser definido tanto como um conjunto de recursos, reais e potenciais, ligados por uma rede de relações de interesses, durável e institucionalizada, quanto como o reconhecimento interno e externo ao sistema (FRANCO, 2001). Neste sentido, o sistema de gestão dos recursos hídricos transcende o papel de mero instrumento gerencial na medida que gera e mantém relações políticas, com base em processos científicos de tomada de decisão, mas também, exige, para o seu funcionamento, a construção do consenso e de decisão sustentada pela confiança entre os atores.

Em nossas sociedades cada vez mais fragmentadas, a conformação de uma esfera pública democrática depende de negociação dos interesses, da aceitação das diferenças e da geração de objetivos comuns que permitam o desenvolvimento de ações solidárias (PEREIRA; JOHNSSON, 2005).

\section{CONCLUSÕES}

A implantação dos comitês de bacia, como parte integrante do Sistema Nacional de Gerenciamento de Recursos Hídricos proporcionou grandes avanços a gestão de recursos hídricos, aproximando a mesma da população.

No entanto, a abertura de novas formas de participação na gestão, muitas vezes, é aproveitada de forma contraditória, pois uma grande parcela da popu- lação não possui conhecimento a cerca da importância de sua participação nos comitês, deliberando sobre a gestão eficiente dos recursos hídricos, e outros utilizam essa ferramenta para promover a manipulação em prol de seus interesses.

O grande desafio é que esses espaços sejam efetivamente públicos, tanto no seu formato quanto nos resultados, e para tal os comitês devem passar por um processo de avaliação e planejamento, fazendo com que realmente os comitês funcionem como um fórum integrador de políticas, promovendo a gestão integrada e sustentável dos recursos naturais da bacia hidrográfica.

\section{REFERÊNCIAS}

ABERS, R.; KECK, M. Comitês de bacia no Brasil uma abordagem política no estudo da participação social. R. B. Estudos Urbanos e Regionais, V. 6, N. 1 / Maio 2004.

ANDREOZZI, S. L. Planejamento e Gestão de Bacias Hidrográficas: Uma Abordagem Pelos Caminhos da Sustentabilidade Sistêmica. Tese (Doutorado). Programa de Pós-Graduação em Geografia - UNESP. Rio Claro, UNESP, 2005.

BARBOSA, H. B. O Desafio da Gestão Integrada: Recursos Hídricos na Grande São Paulo. 2003. Dissertação (Mestrado). Curso de Pós-graduação da Escola de Administração de Empresas de São Paulo, Fundação Getulio Vargas, São Paulo, 2003.

CARDOSO, M. L. de M. Desafios e potencialidades dos comitês de bacias hidrográficas. Cienc. Cult. vol.55, nº 4, São Paulo. 2003.

\section{COMITÊ DE GERENCIAMENTO DA BACIA} HIDROGRÁFICA DO RIO CAMAQUÃ - CBHC. Composição. Disponível em: < http://www.comitecamaqua. com> Acesso em: 5.jul.2013.

\section{COMITÊ DE GERENCIAMENTO DA BACIA HIDROGRÁFICA DO RIO SANTA MARIA - CBHSM. Composição 2012-2014. Disponível em $<$ http://www.comiterio santamaria.com.br.> Acesso em: 10 jul. 2013.}

COSTA, F. J. L. Debates. In: Monticeli, João Jerônimo (Coord.). Organismos de Bacias Hidrográficas. Rio de Janeiro: Semads, p. 17-28, 2002.

DULAC, V. F.; BAGGIOTTO, C.; CRUZ, J. C.; CONSENSA, C. B. Classificação das deliberações e 
projetos aprovados pelo Comitê de Bacia Hidrográfica do Rio Santa Maria. $3^{\circ}$ Congresso Internacional de Tecnologias para o Meio Ambiente, Bento Gonçalves, 2012.

FRACALANZA, A. P.; CAMPOS, V. N.; MEDEIROS, Y. D. Governança das águas da região metropolitana de São Paulo (Brasil) - o caso do Comitê da Bacia Hidrográfica do Alto Tietê. In: Dimensões político institucionais da governança da água na América Latina e Europa. São Paulo: Annablume, p. $42-59,2009$.

FRANCO, A. Capital Social. Cidade: Instituto de Política. Millennium, 2001.

GUIVANT, J.; JACOBI, P. Da hidrotécnica à hidro -política: novos rumos para a regulação e gestão dos riscos ambientais no Brasil. Cadernos de Pesquisa Interdisciplinar em Ciências Humanas, Florianópolis/ Universidade Federal de Santa Catarina, n. 43, 2003.

JACOBI, P. R.; FRACALANZA, A. P. Comitês de bacias hidrográficas no Brasil: desafios de fortalecimento da gestão compartilhada e participativa. Desenvolvimento e Meio Ambiente, n. 11-12, p. 41-49, jan./dez. 2005.

JACOBI, P. R. Participação na gestão ambiental no Brasil: os comitês de bacias hidrográficas e o desafio do fortalecimento de espaços públicos colegiados. En publicacion: Los tormentos de la materia. Aportes para una ecología política latinoamericana. Alimonda, Héctor. CLACSO, Consejo Latinoamericano de Ciencias Sociales, Buenos Aires. Marzo 2006.

JACOBI, P. R.; BARBI, F. Democracia e participação na gestão dos recursos hídricos no Brasil. Rev. Katál. Florianópolis, v. 10, n. 2, p. 237-244, jul./dez. 2007.

HAASE, J. O Encontro Estado e Sociedade na Política Gaúcha das Águas. 315p. Tese de Doutorado em Ecologia, Universidade Federal do Rio Grande do Sul, Porto Alegre, 2005.

KEMERICH, P. D. da C.; MARTINS, S. R.; KOBIYAMA, M.; BURIOL, G. A.; CRUZ, R. C.; RITTER, L. G.; DULAC, V. F. Efetividade do comitê de gerenciamento de recursos hídricos na bacia hidrográfica dos Rios Vacacaí e VacacaíMirim. Recursos hídricos, v. 34, n. 2, p. 13-24, 2013. estudos em geografia humana. Ver. Geografia (Londrina), v. 14, $\mathrm{n}^{\circ} 2,2005$.

MACIEL, P. Debates. In: Monticeli, João Jerônimo (Coord.). Organismos de Bacias Hidrográficas. Rio de Janeiro: Semads, p. 17- 28, 2002.

MAGALHÃES Jr, A. Variáveis e desafios do processo decisório no contexto dos Comitês de Bacia Hidrográfica no Brasil. Ambient. soc., $\mathrm{n}^{\circ} .8$, p.21-48, 2001.

MASCARENHAS, A. C. Comitê de Bacia Hidrográfica: O Que é, Como Funciona, e que Papel Desempenha na Gestão dos Recursos Hídricos. In: Plenarium, ano III, n. 3. Brasília: Câmara dos Deputados, Coordenação de Publicações, 2006.

MEIER, M. A. A conjuntura dos instrumentos da política estadual de recursos hídricos do estado do Rio Grande do Sul. 238 p. Dissertação (Mestrado). Universidade Federal de Santa Maria, Centro de Ciências Naturais e Exatas, Programa de Pós-Graduação em Geografia e Geociências, RS, 2011.

NASCIMENTO, W. M. do; VILLAÇA, M. G. Bacias hidrográficas: planejamento e gerenciamento. Revista Eletrônica da Associação dos Geógrafos Brasileiros - Seção Três Lagoas, MS, $\mathrm{N}^{\circ} 7$, ano 5 , 2008. Disponível em: <http://www.cptl.ufms.br/ revista-geo/Art507_W.Nascimento_M.Vila\%E7a. pdf $>$. Acesso em 25 abr. 2013.

PAIM, P. Paulo Paim: Entrevista [julh. 2010]. Entrevistador: M. A. Meier. Porto Alegre: DRH-RS, 2010. $1 \mathrm{~cd}$ sonoro. Entrevista concedida ao projeto "A conjuntura dos instrumentos de gestão da Legislação dos Recursos Hídricos no Estado do Rio Grande do Sul”. 2010.

PEREIRA, D. S. P.; JOHNSSON, R. M. F. Descentralização da gestão dos recursos hídricos em bacias nacionais no Brasil. REGA, Vol. 2, no. 1, p. 53-72, jan./jun. 2005.

TUNDISI, J. G. Novas perspectivas para a gestão de recursos hídricos. Revista USP, São Paulo, n.70, p. 24-35, jun./ag. 2006.

LIMA, A. G. A bacia hidrográfica como recorte de 